\title{
La Violencia en las Célebres Obras Teatrales Españolas
}

Likae Mohamed Bachir Hassan

Universidad de Bagdad- College de Lenguas

Departamento español

licamohamed@yahoo.com

Submission: 217 at $11 \backslash 5 \backslash 2017$

Abdullah: 436 at 19 $\backslash 7 \backslash 2017$

\section{Abstract:}

Violence in the customs of the Spanish society is very diverse, and this will try to explain in the plays that have had great success in the Spanish stages throughout the centuries.

The plays are many, but I have chosen the most famous starting with the work La Celestina in the XV century of Fernando de Rojas, giving a brief summary of the biography of the author, and then argumneto of the work presented through violence action. and ending with the work of the XX century inadvertently Hyacinth Benavente.

\section{العنف في اشهر الاعمال المسرحية الاسبانية I. إم. لقاء محمد بشهيرحسن

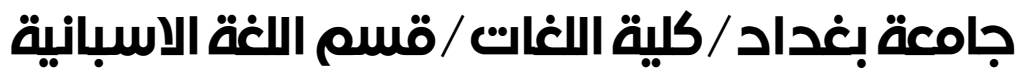 licamohamed@yahoo.com}

\section{الملخص:}

يوجد عنف متتوع في عادات المجمع الاسباني، وسأحاول طرح ذلك من خلال ملخص المسرحيات الاسبانية الثهيرة التي نالت نجاحات ساحقة عبر العصور ـ والهدف من هذا البحث هو

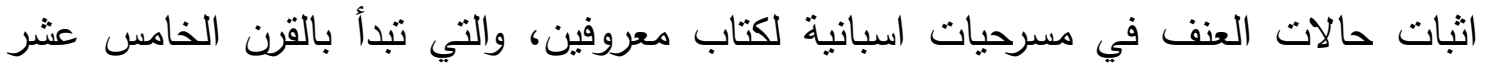

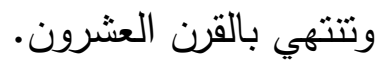

كثيرة هي تلك الاعمال المسرحية، لكن اخترت الاكثر شهرةً منل: (لاتلستينا) التي عرضت في القرن الخامس عشر، و (حفلات مدريد) عرضت في القرن السادس عشر، و (فونت اوفخونا) في

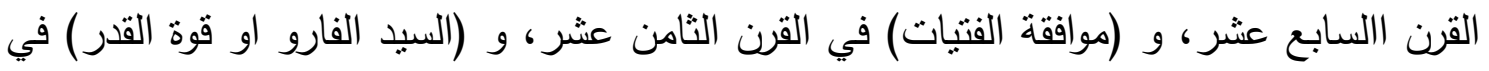
القرن التاسع عشر، و (حظيرة نحو الموت) في القرن العشرون.

كانت معظم هذه المسرحيات نهاياتها مأساوية، والخيانة والعنف كان فئرة واضحاً في احداث فصول

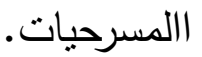




\section{-Resumen de la Investigación:}

En esta investigación se pondrá a conocer unas obras teatrales famosas de escritores españoles, en las que se observará la violencia a través de los sucesos de cada obra.

He tomado las célebres obras según los siglos empezando por el siglo $\mathrm{XV}$, y terminando con el sigloXX.

\section{Introducción:}

La violencia en las costumbres de la sociedad española es muy diversa, y esto lo intentaré exponer en las obras teatrales que han tenido un gran éxito en los escenarios españoles a lo largo de los siglos.

Las obras dramáticas son muchísimas, pero he escogido las más famosas empezando con la obra La Celestina en el siglo XV de Fernando de Rojas, dando un breve resumen sobre la biografía del autor, y después el argumneto de la obra que presentará la violencia a través de la acción.

He elegido en el siglo XVI la obra Las Ferias de Madrid de Lope de Vega; en el siglo XVII la obra Fuente Ovejuna también del gran genio del teatro español que es Lope de Vega; como también en el siglo XVII la obra la vida es sueño del célebre Calderón de la Barca; en el siglo XVIII la obra El Sí de las Niñas de Moratín; en el siglo XIX la obra Don Álvaro o la Fuerza del Sino del Duque de Rivas; en el siglo XX la obra Escuadra hacia la muerte de Alfonso Sastre y por última obra escogida en está investigación será Sin Querer de Jacinto Benavente también marca el siglo XX.

I-El Siglo XV: - La obra de La Celestina de Fernando de Rojas:

El autor de está obra fue durante mucho tiempo ignorado acerca de la autoría de la obra. Se da como seguro que fue Fernando de Rojas, que nació en Puebla de Montalbán (Toledo), probablemente en 1476. Estudió leyes en la Universidad de Salamanca y llegó a ser Alcalde Mayor de Talavera (Toledo), donde murió en el año 1541.

En el prólogo, dijieron que Rojas después de leer el primer acto de la obra que estaba entre los estudiantes de la universidad. Le atrayó y se decidió continuar escribiendo la obra en los siguientes actos, terminandolos en 15 días. 1

- $\quad$ Argumento y análisis de la obra:

En La Celestina se observa el trágico amor de Calisto y Melibea y la mala intención que emplea la alcahueta Celestina para explotar ese amor. Calisto, fue un mozo inteligente y de clase alta, había conocido en una huerta, algo alejada de la cuidad, a la bellísima Melibea, y se enamoró de ella. Vuelve a encontrársela en la ciudad, cerca de la iglesia, y le comunica sus sentimientos. 
Calisto confiesa que está enamorado de Melibea a su criado Sempronio. Éste le sugiere que le pida ayuda a la vieja Celestina como intermediaria, para que levanté el amor de Melibea.

Celestina pudó acercarse a Melibea y consiguió hacerla interesada por Calisto. Sempronio y Pármeno, que son los criados de Calisto, se ponen acuerdo con la Celestina, y deciden aprovechar a su amado por la ayuda que le ofrecieron, y por su parte Calisto ofrece a la vieja una cadena de oro. Los criados no se ponen deacuerdo con la vieja, y la matan. Después son prendidos por la justicia.2

Calisto visitaba Melibea en su jardín trepando por una escalera de cuerda; un día se resvaló, cayó y es muerto por la caída de la escalera. Melibea, al saber eso, sube a una torre y se arroja desde lo alto. La obra termina con el llanto de Pleberio, padre de Melibea.2

Lo destacado en esa obra son los personajes y la lengua sencilla y popular. La violencia se nota en los explotadores que son la Celestina y los criados que intentaron aprovechar el amor de Calisto y Melibea. Y el espíritu maligno que tenían. 3

II-EL Siglo XVI:- La Obra Las Ferias de Madrid de Lope de Vega:

Félix Lope de Vega y Carpio (Madrid, 1562-1635) fue uno de los más importantes poetas y dramaturgos españoles del Siglo de Oro y, escribió muchas obras literarias, y obtuvó el grado de autor universal en la literatura.

Las Ferias de Madrid, es una obra en tres jornadas, escrita en la etapa de la juventud de Lope de Vega. La fecha de la composión de la obra fue en 1586 y publicada en 1589. Era una verdadera obra maestra dentro del teatro del Siglo de Oro español. 4

\section{- $\quad$ Argumento y análisis de la obra:}

"La obra se conoce como un "role-playing", porque se nos ofrece con un fin trágico. Violante y Leandro se conocen, ella estaba haciendo un papel de labradora sin revelar su verdadera identidad. Entre este primer encuentro de los amantes y los siguientes ocurre otro hecho igual de importancia: el papel que adopta Patricio al llamarse "Alejandro" y ganarse la confianza de Leandro hasta el extremo de saber cuándo y dónde están citados Leandro y Violante. Patricio había faltado a la cama conyugal desde la fecha de su boda; la breve escena entre Eugenia y el paje ocurrida en medio del bullicio de la primera jornada destacan lo celoso que es Patricio para con su amante, contrastando esto con el poco caso que ha hecho a su mujer hasta el momento de entrar Leandro en escena. Cuando aparece Violante en la primera jornada, está haciéndose pasar por labradora ocultando su verdadera identidad; su salida contrasta con la de Eugenia y Eufrasia, que llegan a la feria de San Mateo tapadas, hasta el extremo de que Eufrasia, 
bajo su anonimidad de tapada, logra que su propio marido la festeje; ella está haciendo su propio papel para demostrar a su marido el peligro que corre al intentar cortejar a esas tapadas que van a la feria. El efecto escénico de la muerte de Patricio en circunstancias justificadas por las palabras del padre, que reflejan en realidad la vergüenza que ha sentido durante los años de flagrante amorío de su yerno, deshonra de su casa, y dice Belardo a Patricio:

¡Ah, Patricio, Patricio! Que con ella

Hiciste aquesta indigno casamiento enamorado y loco por tu amiga,

que, por ventura, a tal maldad te obliga.

Leandro llega y entra en seguida en casa de Violante. Patricio, que se ha asegurado de que su suegro le haya visto entrar, le exige que mate a los dos. Belardo, impresionado por lo que acaba de ver, dice:

Belardo se arrodilla ante su yerno y pide que lo haga Patricio, pero éste vuelve a insistir en que lo haga él. Belardo, en vez de matar a su hija y Leandro, mata a Patricio.

Esa muerte sobresale, dramáticamente, por la manera tan inesperada en que se produce, y se pone de relieve por el detalle de los enmascarados que cruzan el escenario sin darse cuenta de la tragedia que han presenciado. Patricio muere en el olvido, anónimo, en realidad, y su muerte está justificada, por las circunstancias. Quizá esta obra no es un ejemplo de "poetic justice" pero cuando se considera las veces que Patricio señala su propia falta de concepto moral, se simpatiza con la actitud del padre y de Violante y la muerte del marido adúltero que parece justa y merecida.

Se puede decir que Las Ferias de Madrid, es una obra de la juventud de Lope que es una comedia que lleva dos corrientes paralelas, una el ambiente alegre y ligero de Las ferias... y la otra el adulterio de Patricio y los intentos contra el honor de Violante, que producen la muerte de Patricio y no la de Violante como se esperaba tras el diálogo entre suegro y yerno. Lope va en esta obra en contra de las "reglas" tan respetadas en otras culturas y en distintas épocas, pero en cambio nos muestra la capacidad de improvisar sus propias reglas, o sea, su afán de no respetar ninguna, excepto la de acción." Se observa la violencia de las costumbres humanas, como también el final trágico del protagonista que tenía la culpa por no haber complacido a su mujer como tampoco hizo alguna solución para evitar la relación de Violante con Leandro.5 
III-1.Siglo XVII:- La Obra Fuente Ovejuna de Lope de Vega:

Fuente Ovejuna (1619) es una obra del teatro barroco, escrita por Lope de Vega, en la que el pueblo de Fuenteovejuna se revela contra la injusticia y los abusos de poder que tenía lugar en aquel entonces.

- $\quad$ Argumento y análisis de la obra:

Esa obra presenta un evento histórico que tuvó lugar en Fuente Ovejuna, un pueblo cordobés, en 1476.

Fernán Gómez de Gúzman fue el Comendador del pueblo, y no respetaba las leyes y abusaba de su poder; traicionaba los principios feudales y se comportaba como un tirano. Traicionaba al puebo y a los Reyes Católicos, en aquella época.

Laurencia era la hija del alcalde, dice a una amiga que el Comendador, tenía fama de aprovecharse de las mujeres del pueblo, y que la querría ser amante suya a Laurencia, pero lo renunció.

Laurencia es obligada por El Comendador a ir forzada al palacio. Y al llegar Frondoso ( amante de Laurencia) la rescata del Comendador. El Comendador se pone furioso porque Laurencia se fugo con su amante y quiere matar a Frondoso. En la boda de Frondoso y Laurencia el Comendador hace detener a los novios.

Todo el pueblo se pone harto de los robos, atropellos y crueldades del Comendador, y deciden unirse y matarle en nombre de Fuente Ovejuna y los Reyes Católicos.

La obra se compone de tres actos. En los tres actos había el bien y el mal, pero claro estaba , a través de los sucesos de la obra que sobresalió el bien en el primer y tercer acto.

En la justicia, todo el pueblo de "Fuente Ovejuna" confiesa que ha matado al Comendador. Y piden el perdón de los Reyes Católicos

La tragicomedia termina con la gestión de los Reyes Católicos de la Ciudad Real y unen Fuente Ovejuna a su reino.

El estilo, fue el de un lenguaje social usado por los personajes que puso Lope de Vega con la métrica, que es de arte menor, como las redondillas y los romances.

La corrupción fue una de las características más destacadas de la época barroca, y se notó en esta obra, en la condición del pueblo. La violencia que se observa en el abuso del Comendador de las mujeres de la villa, el intento de apoderarse de la Ciudad Real y el rapto de los novios en su noche de boda. 6 
III-2. Siglo XVII: La obra la vida es sueño de Calderón:

Pedro Calderón de la Barca nació en (Madrid, 1600-1681) de familia hidalga. Se educó en el Colegio Imperial de los Jesuitas en Madrid, en el que se familiarizó con los poetas clásicos latinos. En 1614 se matricula en la Universidad de Alcalá y, el año siguiente, en Salamanca, donde estudió Cánones y Derecho hasta 1620.1 rey que es ruerte?

- $\quad$ Argumento y análisis de la obra:

" La vida es sueño (1635) plantea el tema de la libertad y el destino; se escenifica la historia el príncipe Segismundo, cuya vida transcurre en la cautividad de una torre por orden de su padre, el rey Basilio, temeroso de que se cumplan los horóscopos que predecían que su propio hijo lo destronaría. Al llegar a la edad adulta, el padre, apenado por la situación de Segismundo, decide comprobar la veracidad del oráculo; para ello, sin previo aviso, lo lleva drogado a palacio y le permite reinar por un día. El príncipe se comporta como un bárbaro, por lo que es devuelto a la prisión; el breve periodo de libertad se le aparece entonces como un sueño. Enterado el pueblo de que Basilio tiene un heredero de su propia sangre, se subleva y libera a Segismundo (jornada III) Éste, aprendida la lección, cambia por completo de conducta, perdona al padre y se comporta con generosidad y prudencia. En adelante sabrá refrenar sus pasiones por si la libertad y el poder han sido sólo un sueño.

"En La vida es sueño Calderón de la Barca pone en escena cuestiones de trascendencia universal, que se inscriben, además, en el centro de la mentalidad barroca: la libertad del hombre frente a las predicciones de las estrellas y el destino adverso; la posibilidad de que nuestra vida sea un breve sueño previo a la imprevisible eternidad; la autoridad del monarca injusto frente a la inminente rebelión de los súbditos. La fuerza de Segismundo resulta indescriptible y algunos de sus monólogos, como el que empieza "Apurar cielos pretendo...", forman parte de la media docena de poemas que hasta no hace mucho identificaba y sabía recitar cualquier hablante de la lengua española. En la escena del acto II, Segismundo, libre por vez primera, da rienda suelta a sus violentos instintos, ante la decepción $\mathrm{y}$ el temor de los que lo rodean.

(Este es el soliloquio más famoso del drama español; ocurre al final del primer acto, cuando Segismundo piensa en la vida y en su suerte.)

Sueña el rico en su riqueza, que más cuidados le ofrece; sueña el pobre que padece prestado, en el viento escribe, y en cenizas le convierte la muerte, ¡jdesdicha fuerte! 
$¿$ Que hay quien intente reinar, viendo que ha de despertar en el sueño de la muerte? 7

IV- El Siglo XVIII:La obra El Sí de las Niñas de Moratín:

La comedia neoclásica representa a la perfección el espíritu ilustrado en los escenarios. En cuanto a su estructura dramática, responde al modelo de la comedia preconizado por Ignacio de Luzán en su Poética. El tema que trataba la obra El Sí de las Niñas fue el matrimonio entre una joven y un viejo que era una frecuencia en la comedia neoclásica española, por la causa del interés material de los padres. Leandro Fernández de Moratín (1760-1828)- el más importante comediógrafo del XVIII- escribió muchas piezas y muy importantes como, El viejo y la niña, El barón y La mojigata. Estudió en los jesuitas de Calatayud.Se conoció como poeta con el romance heroico.Se premió por la Real Academia Española en 1779; y en 1782 también se premió por Lección poética. Sátira contra los vicios introducidos en la poesía española. En 1779 fue secretario del conde de Cabarrús, lo que le permitió visitar varios países europeos, entre ellos Francia y el Reino Unido.

Sus mejores éxitos fueron en el campo teatral. Intentó introducir en España los moldes del teatro neoclásico francés: "Las tres unidades de tiempo, lugar y acción, y la finalidad moralizante".8

- $\quad$ Argumento y Análisis de la obra:

La comedia El Sí de las Niñas (1801) es una comedía célebre e importante de Moratín, el hijo, se trata de tres actos.

En el argumento aparece Paquita que es coaccionada por su madre, doña Irene, para contraer matrimonio con un maduro caballero, don Diego. Paquita está enamorada de un joven militar, llamado Carlos, sobrino de don Diego. Carlos y Paquita, están muy enamorados, pero están dispuestos a dejarse. Al enterarse don Diego de aquel amor entre los jovenes, deja a Paquita y les ayuda a casarse.

"El Sí de las Niñas es una comedia que esta perfectamente construída en cuanto a los personajes y el diálogo. Trató esta obra poner a vista del público una costumbre social muy negativa e intentó resolverla el dramáturgo, también está costumbre es muy frecuente en la sociedad árabe. Todo esto es violencia porque se obliga a la mujer a casarse con quien no quiere casar. 9

V- SigloXIX:- La obra Don Álvaro o la Fuerza del Sino del Duque de Rivas:

El Duque de Rivas es Ángel de Saavedra nació en (Córdoba,1791Madrid, 1865) Poeta y dramaturgo español sus obras tratan los temas del 
romanticismo hispano. Las ideas del Duque de Rivas eran liberales, pues luchó contra los franceses y contra el absolutismo por lo que tuvo que exiliarse a Malta.

La obra Don Álvaro o la Fuerza del Sino fue la base del teatro romántico español y el teatro moderno en España. En esta obra hay factores importantes del romanticismo, como la melancolía o el pesimismo. Su tema principal es el destino desgraciado del hombre. Se estrenó esta obra en el Teatro del Príncipe de Madrid, el 22 de marzo de 1835.10

Argumento y análisis de la obra:

Esta obra tiene lugar a principios del siglo XVIII, en Sevilla, donde reside el protagonista de la obra, don Álvaro que es un rico y misterioso indiano que vive una aventura de amor con doña Leonor, una joven aristócrata; pero esa relación es prohibida por el Marqués de Calatrava, padre de doña Leonor, porque don Álvaro es un vulgar aventurero. Los amantes deciden escaparse pero los pilla el Marqués de Calatrava; al bajar don Álvaro su pistola al suelo, hiere mortalmente al Marqués sin querrer. Los dos hermanos de doña Leonor - don Carlos y don Alfonso- siguen a doña Leonor y don Álvaro para matarlos. La Leonor se siente triste por la muerte de su padre por su culpa, decidió ser monja en un convento, y corta su relación con don Álvaro, que piensa que doña Leonor ha muerto.11

En Italia, don Álvaro conoce a don Carlos, después de la amistad, se entera que es el hermano de su amante y le reta a duelo y allí don Carlos pierde la vida por la espada de don Álvaro, que también causa una segunda muerte sin intención, y decide refugiarse como fraile en el Convento de los Ángeles.

Don Alfonso, el otro hermano de doña Leonor, se pone en busca del criminal don Álvaro vengar a su padre y hermano. Al encontrarle le desafía un duelo, y también don Álvaro hiere mortalmente a don Alfonso, pero antes de morir mata a su hermana doña Leonor al creer que ella vivía junto al convento de don Álvaro, que se alegró..12

Don Álvaro, esta desesperado por la muerte de doña Leonor y se siente culpable de todas las muertes y se suicida arrojándose desde un precipicio gritando "Soy un enviado del infierno, soy un demonio exterminador".13

El tema principal en esta obra es la muerte de 3 personas que es violencia absoluta y por las dudas se mata a la protagonista. Y por la tristeza se suicida el protagonista. Todos los sucesos de la obra presentan la violencia que estuvo presente en el siglo XIX . "Al igual que en la francesa Hernani. Cuando el compositor italiano Giuseppe Verdi estrenó en 1862 su ópera La fuerza del destino, basada en esta obra, buscó evitar precisamente la excesiva cantidad de muertes en la trama, por lo cual el artista resolvió permitir que el personaje de Don Álvaro sobreviviera al final de la obra".14 
VI-1. EL Siglo XX: -La obra Escuadra hacia la muerte de Alfonso Sastre : Alfonso Sastre Salvador nacido en (Madrid, 1926), es un escritor, dramaturgo,ensayista,guionista cinematográfico español, y es uno de los principales exponentes de la llamada Generación de 1955, ganó el Premio Nacional de Teatro en 1986. Su trayectoria personal se ha caracterizado por su compromiso político y social y la denuncia del régimen franquista hasta el fin de la dictadura.

Recibió el Premio Nacional de Literatura en la modalidad de Literatura Dramática en 1993. Alfonso Sastre escribió también cuentos de terror, y poesía. El teatro de Sastre, concentra en el contenido y está preocupado por las cuestiones formales y estructurales y es sensible, como se considera una parte del teatro burgués." 15

\section{- $\quad$ Argumento y análisis de la obra:}

Escuadra hacia la muerte es una obra de teatro en dos actos, divididos en seis cuadros. La obra se desarrolla en una hipotética Tercera Guerra Mundial, en ella aparece un escuadrón de cinco hombres, dirigidos por el Cabo Gobán, que son enviados a un puesto de avanzadilla para informar de los ataques enemigos a la retaguardia. Los soldados, carentes de espíritu militar terminan, durante una borrachera, matando a Gobán, al que perciben como un obstáculo para su propia supervivencia."

Y así , Pedro, Andrés, Alfonso, Javier y Luis deciden mantener sus vidas en la misión a la que estan dirigidos . El primero, con sentimiento de arrepentimiento, decide volver con sus filas a sabiendas que será fusilado por traición; Javier se quita la vida, en la creencia de que todo ha sido una trampa de los mandos de su ejército, Andrés y Alfonso escapan y Luis se prepara para continuar con su propia vida. 16

\section{VI-2. EL Siglo XX: -La obra Sin Querer de Jacinto Benavente :}

Jacinto Benavente (Madrid, 1866-1954) era un célebre dramaturgo español, director, guionista y productor de cine español, obtuvó el Premio Nobel de Literatura 1922. Escribió muchas obras que han sido y siguen siendo famosas como el nido ajeno 1894, la noche del sábado1903, los Interese Creados1907, la malquerida1913, sin querer1901 y otras muchas. Argumento y análisis de la obra brevemente:

La obra trata un tema costumbrista, dos primos Luisa y Pepe, a quienes querían sus padres casarles por beneficios económicos, y eso muestra otra visión de violencia que obliga a dos jovenes a casarse sin quererse. La obra tenía un sólo acto en tres escenas. Toda la conversación que tuvieron los primos entre si ocurrió en la casa de Luisa. Al final de la obra cada uno de los protagonistas encuentra en el otro lo que quiere para hacer una familia equilibarada. Y anuncían la boda.17 


\section{- Las Notas:}

1.Ignacio Arellano ; Jesús M. Usunáriz (ed.). El mundo social y cultural de La Celestina. Madrid/Fráncfort: Iberoamericana-Vervuert, 2003. Págs.273-294

2.Stephen Gilman: «Diálogo y estilo en La Celestina». Nueva Revista de Filología Hispánica. VII (1953).Págs.461-469

3.Ignacio Arellano ; Jesús M. Usunáriz (ed.). El mundo social y cultural de La Celestina. Madrid/Fráncfort: Iberoamericana-Vervuert, 2003. Págs.273-294

4.Stephen Gilman: La Celestina: arte y estructura. Taurus. Madrid, 1974. Pág.17

5.Alva V. Ebersole. Colección Siglo de Oro/5. Las Ferias de Madrid y La Vitoria de la Honra de Lope de Vega. Ed. Estudios de Hispanófila. Valencia,1977.Pág.9

6.S. Griswold Morley y Courtney Bruerton. Cronológia de las Comedias de Lope de Vega. Versión española de María Rosa Cartes. Madrid,1968. Ed. Gredos. Pág.244. Véase también Lope de Vega Las ferias de Madrid. Ed.de la Real Academia Española, dirigida por E. Cotarelo y Mori. Vol. V. Madrid, 1918. Págs. 582-623.

7.Alva V. Ebersole. Colección Siglo de Oro/5. Las Ferias de Madrid y La Vitoria de la Honra de Lope de Vega. Págs.10-16

8.Edward M. Wilson y Duncan Moir, «El teatro de Lope de Vega», en Historia de la literatura española, vol. 3: Siglo de Oro: teatro, Barcelona, Ariel, 1985, cap. 3, (6 ${ }^{\text {a }}$ ed. rev.) Págs. 85-154.

9.Jesús de Bustos Tovar. Diccionario de Literatura Universal. Ed. Anaya. Madrid, 1985. Pág. 87

10.José Manuel Cabrales y Guillermo Hernández. Literatura española y Latinoamericana (Edad Media al Romanticismo). Ed. SGEL. Madrid, 2009. Págs.196205

11.José García López. Historia de la Literatura española. Ed.Vicens-vives. Madrid,1988.Págs.353-357

12.José García López. Historia de la Literatura española. Pág.415

13.Jean Canavaggio. Historia de la Literatura española. Tomo V. El Siglo XIX. Barcelona, 1993. Ed. Ariel. Págs. 32,93 y 94.

14.Carlos Ruiz Silva Duque de Rivas Madrid, Espasa-Calpe, Col. Austral, 1991.Págs. $12-15$.

15.Ermanno Caldera Don Álvaro o la fuerza del sino del Duque de Rivas, Madrid, Taurus, 1986.Pág. 22-24. Véase Víctor García de la Concha. Historia de la Literatura Española-Siglo XIX (II). Espasa. Madrid, 1998.Págs. 215-218.

16.Luciano García Lorenzo. El Teatro Español de Hoy. Editorial Planeta. Barcelona, 1975. Págs. 133

17.José Manuel Cabales y Guillermo Hernández . Literatura española y Latinoamericana del Romanticismo a la actualidad. Ed. SGEL. Madrid, 2009. Pág. 551

18.John Van Horne, Ph.D. Tres Comedias (Sin Querer, De Pequeñas Causas y Los Intereses Creados). Printed by The Riverside Press. London, 1948. Págs.3-16 